\title{
Performance Analysis of Clear Sky Global Horizontal Irradiance Models: Simple Models Adapted for Local Conditions
}

\author{
Nicholas Kwarikunda $\mathbb{D}^{1}$ and Zivayi Chiguvare $\mathbb{D}^{2}$ \\ ${ }^{1}$ Department of Physics, Makerere University, P.O. Box 7062, Kampala, Uganda \\ ${ }^{2}$ Department of Physics, University of Namibia, Private Bag 13301, Windhoek, Namibia \\ Correspondence should be addressed to Nicholas Kwarikunda; nicholas.kwarikunda@mak.ac.ug
}

Received 5 May 2021; Accepted 11 September 2021; Published 27 September 2021

Academic Editor: Koray Ulgen

Copyright (C) 2021 Nicholas Kwarikunda and Zivayi Chiguvare. This is an open access article distributed under the Creative Commons Attribution License, which permits unrestricted use, distribution, and reproduction in any medium, provided the original work is properly cited.

\begin{abstract}
Evaluation of the maximum solar energy potential of a given area for possible deployment of solar energy technologies requires assessment of clear sky solar irradiance for the region under consideration. Such localized assessment is critical for optimal sizing of the technology to be deployed in order to realize the anticipated output. As the measurements are not always available where they are needed, models may be used to estimate them. In this study, three different models were adapted for the geographical location of the area under study and used to estimate clear sky global horizontal irradiance (GHI) at three locations in the subtropical desert climate of Namibia. The three models, selected on the basis of input requirements, were used to compute clear sky GHI at Kokerboom, Arandis, and Auas. The models were validated and evaluated for performance using irradiance data measured at each of the sites for a period of three years by computing statistical parameters such as mean bias error (MBE), root mean square error (RMSE), and the coefficient of determination $\left(R^{2}\right)$, normalized MBE, and normalized RMSE. Comparative results between modelled and measured data showed that the models fit well the measured data, with normalized root mean square error values in the range $4-8 \%$, while the $R^{2}$ value was above $98 \%$ for the three models. The adapted models can thus be used to compute clear sky GHI at these study areas as well as in other regions with similar climatic conditions.
\end{abstract}

\section{Introduction}

Deployment of solar energy technologies for solar photovoltaic (PV) or thermal applications requires an assessment of the solar energy resource available at the location of interest. Quite often, such measurements may not be available for that location and so have to be estimated under clear sky conditions [1-3]. In some areas, even when measurements are available, gaps may exist in the measurement records that may need to be filled up to efficiently characterize the resource $[4,5]$. Clear sky irradiance, in particular, the global horizontal irradiance (GHI), provides information about the maximum possible solar energy resource available at the location under consideration, which is crucial in estimating or forecasting the performance of solar energy technologies [6]. It is therefore important to estimate, locally, the clear sky GHI in order to forecast the optimal performance of the solar technologies before deployment.

Different kinds of models for clear skies, with varying levels of complexity and input parameters, have been developed over time to estimate clear sky global solar irradiance for various solar energy conversion applications especially in areas where the measurements are not available. These models are either based on empirical expressions [7-9] or may be broadband [10, 11]. Empirical-based irradiance models require geometric parameters such as zenith angle and or basic meteorological parameters such as sunshine hours, relative humidity, pressure, clearness index, and temperature $[12,13]$ as input parameters, while the broadband irradiance models require parameters that characterize the atmospheric conditions in detail, including but not limited to parameters such as aerosol optical depth, amount of precipitable water, and ozone column $[1,14-16]$. 
Quite often, however, these detailed atmospheric or meteorological parameters are not always available or where they are available, they are of low quality and thus will limit the accuracy of the outputs from the models $[16,17]$. Satellite images have also been used to estimate solar irradiance on the Earth's surface, for example, the authors of [18-22] developed statistical and semiempirical methods to determine global solar radiation at ground level using data from geostationary meteorological satellites. These, however, still face some practical difficulties such as lack of reliable aerosol information, which affects the accuracy of the estimations, especially under clear sky conditions [11, 23]. Artificial neural networks (ANNs) have also been used to compute solar irradiance at the Earth's surface, for example, Sahan and Yakut [24] used a suit of meteorological and geographical parameters as inputs to an ANN model to estimate monthly average global solar radiation on a horizontal surface at five locations in the Mediterranean region, Ozgoren et al. [25] developed an ANN model for estimating the monthly mean daily sum of global solar radiation using meteorological data of 31 stations across Turkey, Kumar and Kaur [26] used five parameters, i.e., temperature, pressure, relative humidity, precipitation, and clearness index as input parameters for a feed-forward neural network to estimate solar radiation in the Hamirpur region in India, while Hasni et al. [27] were able to estimate the global solar radiation for Bechar city in the south western region of Algeria using only air temperature and relative humidity in addition to hour, day, and month of the year. As highlighted, these artificial neural networks also require meteorological data as input parameters, in addition to temporal and geographical parameters. Though these models require detailed inputs to accurately characterize the state of the atmosphere, the availability and or quality of such inputs is not always guaranteed, which therefore limits their accuracy [17]. The use of inaccurate input data in an otherwise complex model may result in poor performance of the model.

Selecting which clear sky model or models to use may depend on the accuracy of the models and the availability of the input parameters. Most of these parameters, which are mainly atmospheric or meteorological parameters, may not be readily available, as already mentioned. This is often the case, in developing countries, due to lack of the necessary measuring equipment that are quite often very expensive and require regular maintenance, thus making them unaffordable to most developing countries $[28,29]$. As such, we propose to adapt and use simple models based on basic input parameters, but with enough accuracy to estimate the localized clear sky global horizontal irradiance in areas where such measurements may not be available. This will be based on computation of solar zenith angle, a primary parameter that determines the magnitude of solar irradiance at any location and time on typical clear sky days [30,31], especially in areas where atmospheric parameters such as water vapor show little or no fluctuation [2]. Clear sky GHI at three different locations in Namibia, which is characterized by a subtropical desert climate with very low humidity, will be computed and discussed. The results will be validated using clear sky ground-based measurements at these locations.
The rest of the paper is organized as follows: in Section 2, we present an overview of clear sky conditions and the detection approaches and models used in the study. Section 3 explains materials and methods used, while Section 4 presents the results and discussions, with concluding remarks in Section 5.

\section{Clear sky Conditions}

Clear sky days are in general characterized by absence of visible clouds across the entire sky dome. Depending on the amount, relative position in the sky, and their optical properties, clouds lead to fluctuations in the GHI due to their impact on the direct and diffuse components of the global irradiance [32, 33]. For example, Abhnil et al. [34] reported significant seasonal changes in the direct normal irradiance (DNI) over Australia that were attributed to clouds, while Tapakis \& Charalambides [35] noted that the presence of clouds in the sky is one of the major unpredictable factors affecting amount of irradiance reaching the Earth's surface. Gueymard et al. [36] reported that the presence of bright clouds in the sky may increase the diffuse component of the global irradiance compared to what it would be in their absence, thus resulting in overall increase in the GHI, while the normal component and hence the GHI will be reduced if clouds obstruct the sun's disc. The degree of cloudiness is quantified in various ways such as human observation of cloud cover, use of ground-based measurements such as sky cameras, sunshine duration and irradiance measurements or from space-based instruments aboard satellites [9, 36-38], all with varying levels of accuracy. Though the method used to determine a clear sky day may depend on the measurements available at the site under consideration, the use of an incorrect or inaccurate clear sky detection method may lead to incorrect conclusions. It is, however, important to note that even in the absence of visible clouds, other atmospheric parameters such as aerosols, precipitable water, or generally hazy conditions that affect atmospheric transmittance can vary in time and space, hence affecting the amount of solar irradiance reaching the surface of the Earth $[17,38]$.

2.1. Detection of Clear sky Days. Various methods have been used to characterize sky conditions and identify clear sky days based on the absence or presence of clouds across the entire sky dome, for example, by visually evaluating the smoothness of the plot of GHI as a function of time of the day [36]. This method is simple but subjective as there is no standard metric for assessing the smoothness of the irradiance curve. An alternative method widely used is based on the computation of the clearness index, $K_{t}$, defined as the ratio of the global solar irradiance measured at the surface to the extraterrestrial solar irradiance, i.e., $K_{t}=H / H_{0}$, where $H$ is the global irradiance and $H_{0}$ is the extraterrestrial solar irradiance. These parameters can be computed over a given period of time such as daily or monthly. The daily extraterrestrial solar irradiance is given as follows [39]: 


$$
H_{0 d}=\frac{24}{\pi} I_{s c} E_{0}\left[\left(\frac{\pi}{180}\right) \omega_{s} \sin \delta \sin \varphi+\cos \delta \cos \varphi \cos \omega_{s}\right],
$$

where $I_{s c}=1367 \mathrm{~W} / \mathrm{m}^{2}$ is the solar constant, $\omega_{s}$ is the sunrise hour angle, $\varphi$ is the latitude of the site under consideration, $\delta$ is the declination, while $E_{0}$ is the eccentricity correction for the Earth's orbit and is given as follows:

$$
E_{0}=1+0.033 \cos \left[\frac{360}{365}(n+284)\right] \text {, }
$$

where $n$ is the day of the year. The declination angle can be approximated as follows [40, 41]:

$$
\delta=23.45 \sin \left[\frac{360}{365}(n+284)\right] .
$$

The clearness index quantifies the extinction of incoming solar radiation due to a combined effect of the various atmospheric parameters such as clouds, aerosols, and water vapor. Very low values of the daily clearness index are an indication of low global irradiance which may mainly be due to the presence of clouds in the sky that obstruct the sun's disc without significantly increasing the diffuse component of the incoming solar irradiance. Different authors have specified varying thresholds of $K_{t}$ that signify a clear sky, for example, Iqbal [39] defined the range of $K_{t}$ for clear sky as $0.7 \leq K_{t}<0.9$, Alves et al. [42] considered the range $0.65<K_{t}<1$ for clear sky, Li and Lam [43] considered $K_{t}>0.7$, while Jung et al. [44] used $K_{t}>0.63$ for clear skies. There is therefore no unique value or range of $K_{t}$ that can be universally designated to represent a clear sky. Djafer et al. $[45,46]$ noted that ranges of $K_{t}$ for clear sky may vary from one measurement site to another. As such, $K_{t}$ should be used in combination with other methods or parameters to identify clear sky days with better accuracy. Another parameter that can be used to specify clear sky is the diffuse fraction, $K$, defined as the ratio of the diffuse to global solar radiation. A value of $K$ less than 0.27 was considered by $\mathrm{Li}$ and Lam [43] to represent clear skies. In this study, clear sky days were identified based on visualization of the smoothness of the GHI curve and computation of daily clearness index and diffuse fraction.

2.2. Clear sky Models. In this article, three simple models adapted for the study area are the Berger-Duffie (B-D) model [47], the Adnot-Bourges-Campana-Gicquel (A-B-C-G) model [47], and the Robledo-Soler (R-S) model [48]. The three models were selected as they only require computation of solar zenith angle as input to the models and so can be used to compute clear sky irradiance in areas where no record of atmospheric parameters is available. The empirical expressions for global horizontal irradiance as estimated by the models are given by equations (4)-(7).

Berger-Duffie (B-D) model:

$$
\mathrm{GHI}=a \cos z \text {. }
$$

Adnot-Bourges-Campana-Gicquel (A-B-C-G) model:

$$
\mathrm{GHI}=a(\cos z)^{b} .
$$

Robledo-Soler (R-S) model:

$$
\mathrm{GHI}=a(\cos z)^{b} \exp \left\{-c\left(90^{\circ}-z\right)\right\},
$$

where $a, b$, and $c$ are empirical constants to be determined and $z$ is the zenith angle.

The zenith angle is given as follows [40, 49]:

$$
\cos z=\cos \varphi \cos \delta \cos \omega+\sin \varphi \sin \delta,
$$

where $\omega$ is the hour angle, obtained as follows [41, 49]:

$$
\omega[\mathrm{deg}]=15(\text { solar time }[\text { hours }]-12) .
$$

\section{Instrumentation, Data, and Methodology}

3.1. Instrumentation and Data. The data used in the study was recorded for a period from January 2016 to August 2018 at three measurement sites in Namibia, i.e., Kokerboom $\left(26.426^{\circ} \mathrm{S}, \quad 18.288^{\circ} \mathrm{E}, \quad 1175 \mathrm{~m} \quad\right.$ a.s.l), Arandis $\left(22.366^{\circ} \mathrm{S}, 15.045^{\circ} \mathrm{E}, \quad 691 \mathrm{~m} \quad\right.$ a.s.l), and Auas $\left(22.589^{\circ} \mathrm{S}, 17.364^{\circ} \mathrm{E}, 1841 \mathrm{~m}\right.$ a.s.l). The global and diffuse horizontal solar irradiance was sampled at 1-minute intervals using a CMP10 pyranometer from Kipp and Zenon, Delft, Netherlands [50], and recorded as ten-minute averages using Campbell Scientific data loggers. For measuring the diffuse irradiance, the pyranometer is equipped with a shadow band. The pyranometers have a spectral range of $285-2800 \mathrm{~nm}$, a nonlinearity below $0.2 \%$ in the range of $100-1000 \mathrm{Wm}^{-2}$, a directional response below $10 \mathrm{Wm}^{-2}$ (up to $80^{\circ}$ with a $1000 \mathrm{Wm}^{-2}$ beam), and a temperature response below $1 \%$ (from $-20^{\circ} \mathrm{C}$ to $+50^{\circ} \mathrm{C}$ ) [50]. In addition, the ambient temperature and the relative humidity at the sites were measured with a Campbell Scientific CS215 temperature and humidity probe. The instruments were installed after calibration and have been regularly maintained by the Namibia Energy Institute (NEI). Data quality checks were carried out to ensure quality measurements. In this regard, days with incomplete or missing data were excluded as well as measurements for which the GHI exceeds extraterrestrial irradiance.

3.2. Methodology. This involved identification of clear sky days based on computation of the daily clearness index, diffuse fraction, and visualization of the smoothness of the GHI curve. For days with a smooth GHI curve, a criterion for a clear sky day was selected by setting a range within which computed values of $K$ and $K_{t}$ must lie. Once these clear days were identified from the measured data, the three models were each used to fit the clear sky GHI data measured at Arandis for a period of one year (January to December 2016), in order to determine the empirical constants for respective models. These measurements were used to fit the models by employing the interval division technique implemented using a custom-developed LabVIEW code. The constants obtained are shown in Table 1. 
TABLE 1: Extracted empirical constants for the three models.

\begin{tabular}{lccc}
\hline Constant & \multicolumn{3}{c}{ Value } \\
& B-D model & A-B-C-G model & R-S model \\
\hline$a\left(\mathrm{Wm}^{-2}\right)$ & 1053 & 1126 & 1119 \\
$b$ & - & 1.20 & 1.19 \\
$c$ & - & - & $1.0 \times 10^{-6}$ \\
\hline
\end{tabular}

Performance of the models was then tested and evaluated at Arandis using data for the period from January 2017 to August 2018 (different from the data used to train the models and obtain the empirical constants) and at two other sites (Auas and Kokerboom, for the period 2016-2018). The performance of the models was evaluated by computing various statistical error parameters such as the root mean square error (RMSE), the mean bias error (MBE), and the coefficient of determination $R^{2}$ values. The RMSE is defined by the following equation:

$$
\operatorname{RMSE}=\left[\frac{1}{p} \sum_{i=1}^{p}\left(\mathrm{GHI}_{i, c}-\mathrm{GHI}_{i, m}\right)^{2}\right]^{1 / 2},
$$

where $\mathrm{GHI}_{i, c}$ and $\mathrm{GHI}_{i, m}$ are the $i^{\text {th }}$ computed and measured global horizontal solar irradiance values, respectively, while $p$ is the number of measurements considered. The RMSE values, in general, demonstrate the overall accuracy of the model, where smaller RMSE values signify a more accurate model. The MBE, which describes the trend of the models in overestimating or underestimating the measured irradiance, is given as follows:

$$
\mathrm{MBE}=\frac{1}{p} \sum_{i=1}^{p}\left(\mathrm{GHI}_{i, c}-\mathrm{GHI}_{i, m}\right) .
$$

Negative values of MBE signify underestimation of the measured values, while positive MBE values indicate an overestimation.

The $R^{2}$ value, which takes on values between 0 and 1 , measures how well the models fit the measured data and is computed as follows:

$$
R^{2}=1-\frac{\sum_{i=1}^{p}\left(\mathrm{GHI}_{i, m}-\mathrm{GHI}_{i, c}\right)^{2}}{\sum_{i=1}^{p}\left(\mathrm{GHI}_{i, m}-(1 / p)\left(\sum_{i=1}^{n} \mathrm{GHI}_{i, m}\right)\right)^{2}} .
$$

Generally, the higher the $R^{2}$ value is, the better the model is at predicting the measured data. The RMSE and MBE were also calculated as normalized percentages of their corresponding mean values using the following equations:

$$
\begin{aligned}
\text { NRMSE } & =\frac{\left[(1 / p) \sum_{i=1}^{p}\left(\mathrm{GHI}_{i, c}-\mathrm{GHI}_{i, m}\right)^{2}\right]^{1 / 2}}{(1 / p)\left(\sum_{i=1}^{p} \mathrm{GHI}_{i, m}\right)}, \\
\mathrm{NMBE} & =\frac{\sum_{i=1}^{p}\left(\mathrm{GHI}_{i, c}-\mathrm{GHI}_{i, m}\right)}{\sum_{i=1}^{p} \mathrm{GHI}_{i, m}} .
\end{aligned}
$$

Equations (12) and (13) give dimensionless NRMSE and NMBE, respectively, which are normally expressed as percentages. These quantities should be as low as possible for better performing models. In evaluating clear sky GHI, NMBE within $\pm 10 \%$ and NRMSE $<20 \%$ would signify good fitting between modelled results and measured data and is quite often used as a quantitative measure for model performance [5].

\section{Results and Discussion}

4.1. Identification of Clear Sky Days. Clear sky days were identified based on the smoothness of the GHI curves, computed daily clearness index, and diffusion fraction values during the period under study. Figure 1 shows the temporal variation of the daily clearness index and the diffuse fraction from January 2016 to August 2018 for the three sites.

The clearness index is characterized by seasonal variation with averagely stable $K_{t}$ during winter period (May to October) and very intermittent $K_{t}$ during the summer period (November to April). The comparatively high intermittency in $K_{t}$ during the summer season is because this period coincides with the rainy season in Namibia with a high rate of occurrence of cloud cover. The winter period is characteristically dry with no or minimal clouds but low irradiance. This seasonal variability has been reported by other authors such as Alves et al. [42], Cuiabá city, Brazil. The frequency distribution of $K_{t}$ and $K$ is plotted in Figure 2, with both figures having a unimodal distribution and showing that more than $60 \%$ of the days considered at all the three stations had $K_{t}$ of 0.7 or more with a $K$ value of less than 0.2 . The daily diffuse fraction is plotted against daily clearness index and is shown in Figure 3, where it is observed that $K$ decreases almost linearly with increasing $K_{t}$, reaching the lowest value of $\sim 0.05$ when $K_{t} \cong 0.72$. Significant scatter in the data is also observed which may be attributed to variation in the daily distribution of radiation caused by changes in the cloudiness states of individual days over the period under consideration. The decrease in $K$ with increasing $K_{t}$ is attributed to clouds. The presence of such clouds may, in addition to blocking of radiation, introduce strongly scattering particles in an otherwise clear sky, thus increasing the diffuse component of radiation [51]. Low $K$ values are an indication that the GHI is mainly dominated by the direct component, signifying absence of clouds. However, relatively high values of $K(K>0.2)$ are also observable for high $K_{t}$ values $\left(K_{t}>0.72\right)$. This is attributed to the existence of partly cloudy skies, with cloud edges reflecting more radiation onto the detector with an otherwise clear view of the sun. Thus, high values of $K_{t}$ alone or low values of $K$ alone may not necessarily represent a clear sky and may thus result in misinterpretation of results, as also observed by Li and Lam [43]. Thus, for this study, clear sky days were identified as those for which $K \leq 0.15$ with $K_{t} \geq 0.72$ and having a smooth GHI curve.

With clear sky days identified based on the above criterion, the corresponding GHI was then computed using the three models with their respective extracted empirical constants. The measured and computed irradiance results on typical clear sky days are shown in Figure 4, where good agreement between measured and modelled irradiance values is observed. 


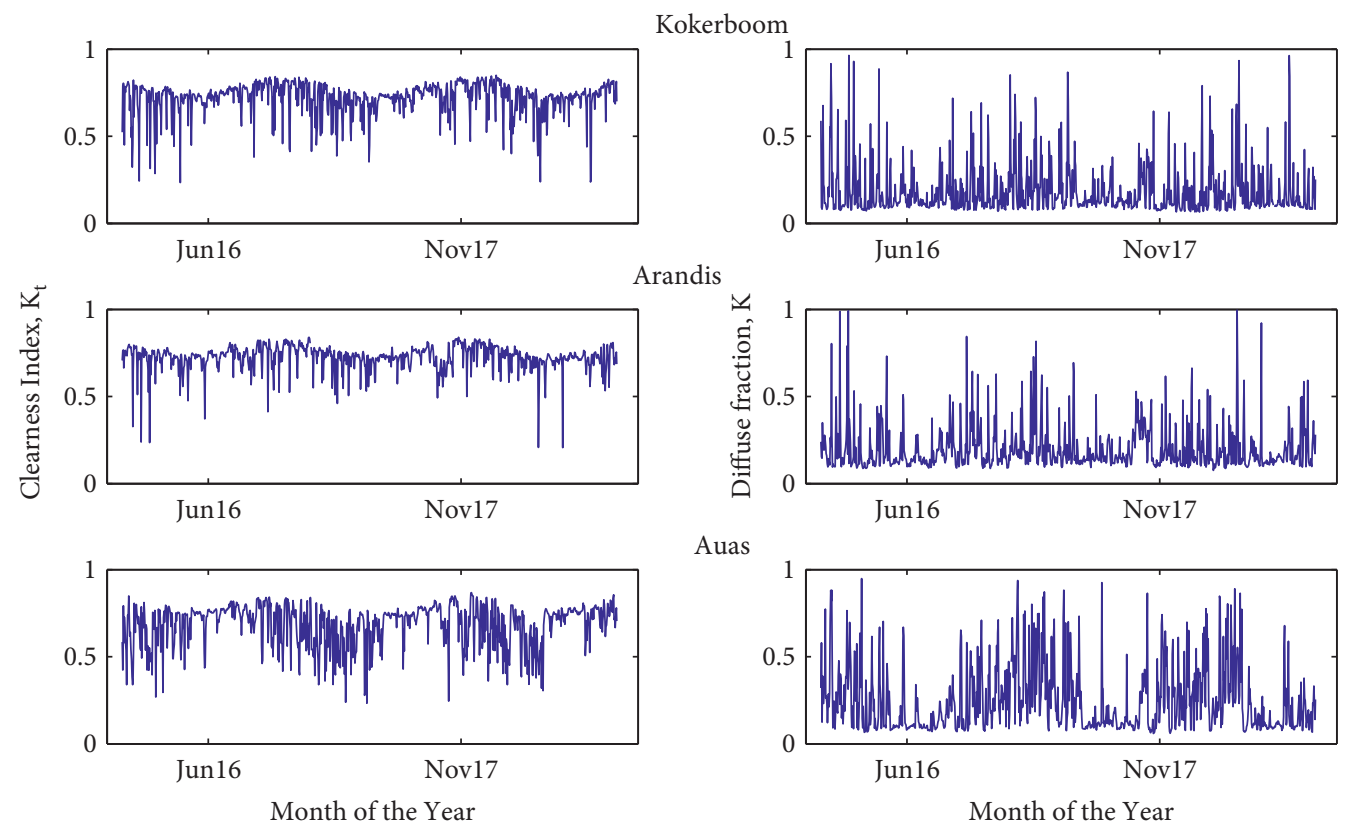

FIgURE 1: Daily variation of clearness index and diffuse fraction at the three measurement sites.
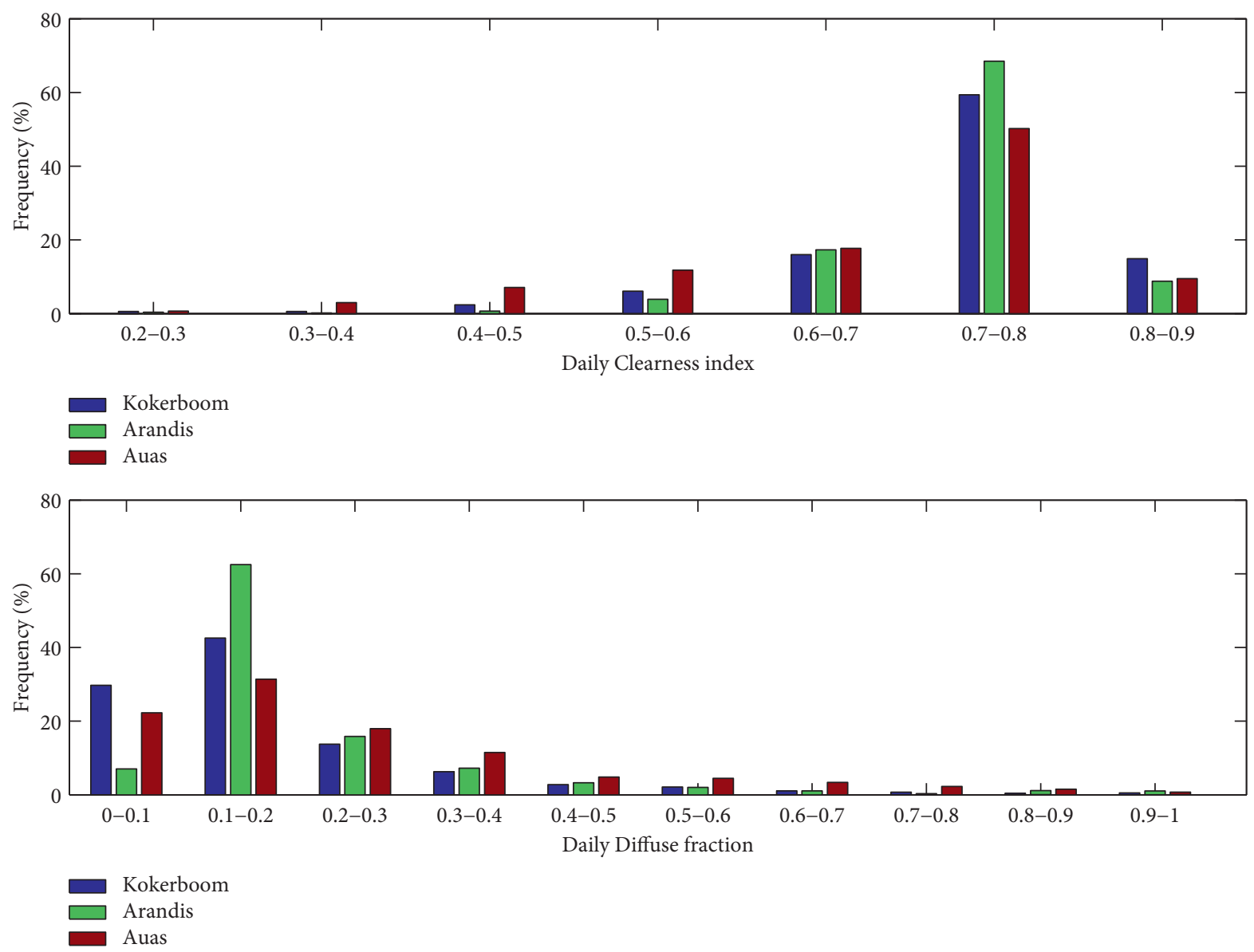

Figure 2: Frequency distribution of Clearness index and diffuse fraction. 

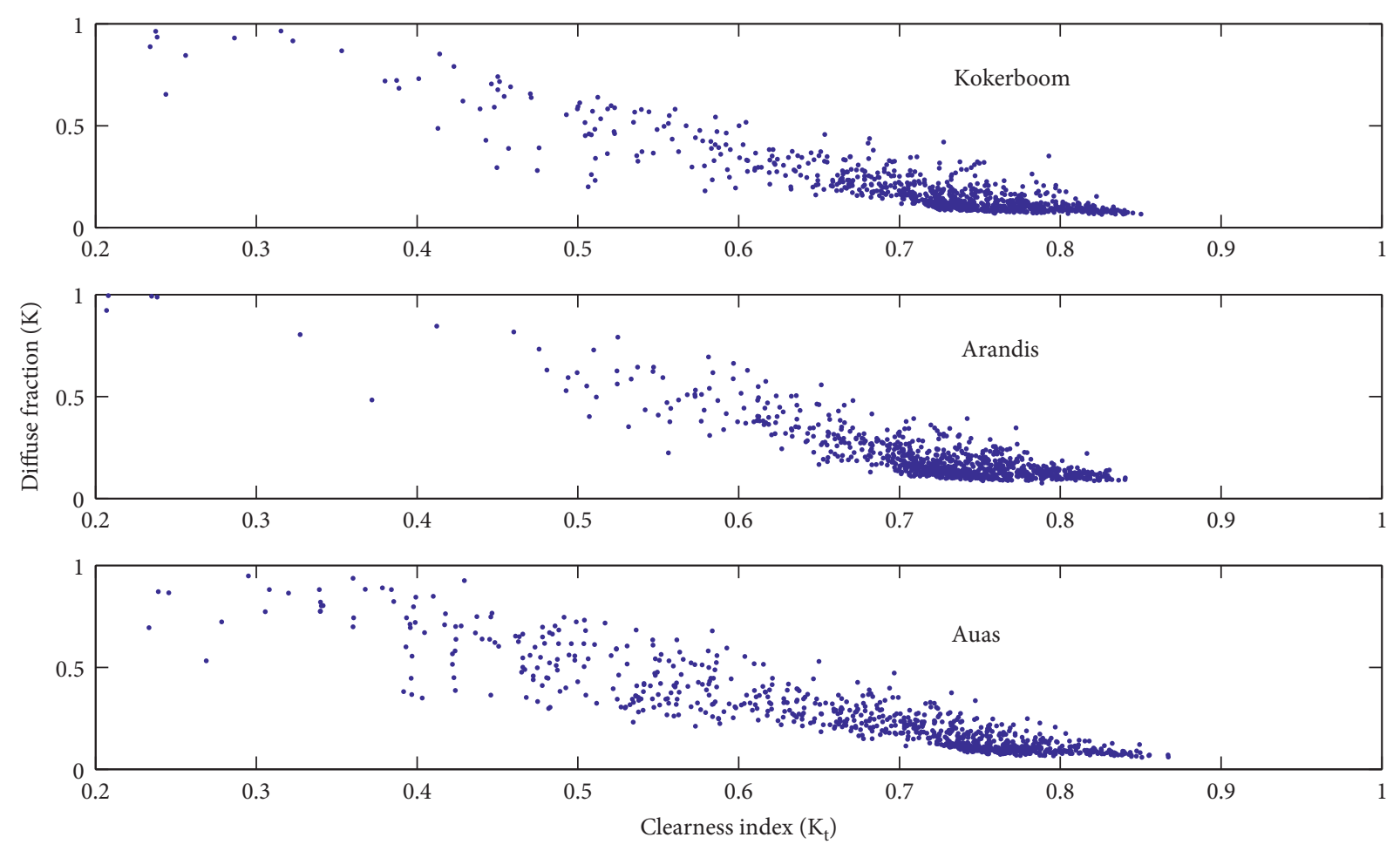

FIgURE 3: Correlation between daily diffuse fraction and clearness index.
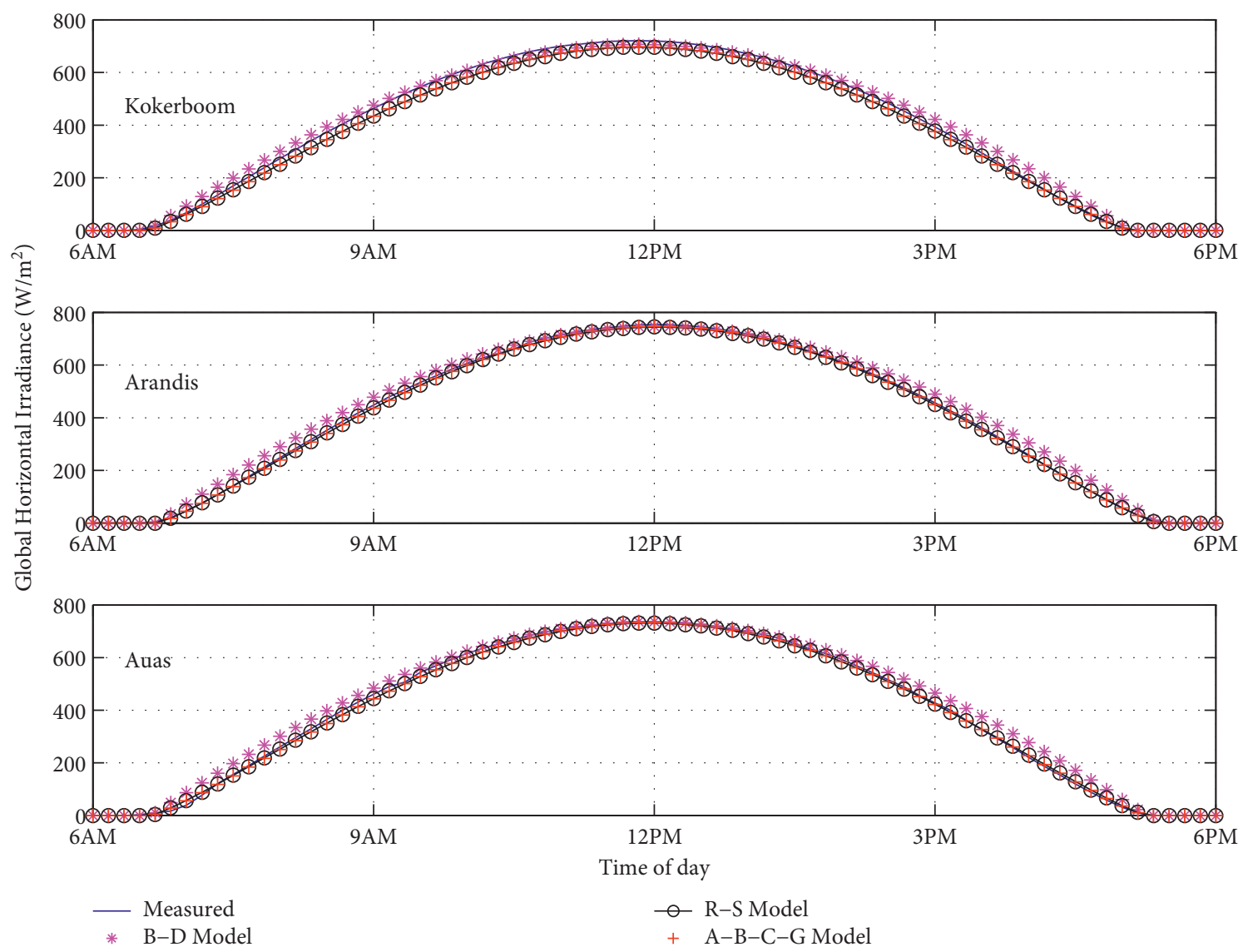

FIgURE 4: Modelled and measured irradiance on typical clear sky days at Kokerboom, Arandis, and Auas. 

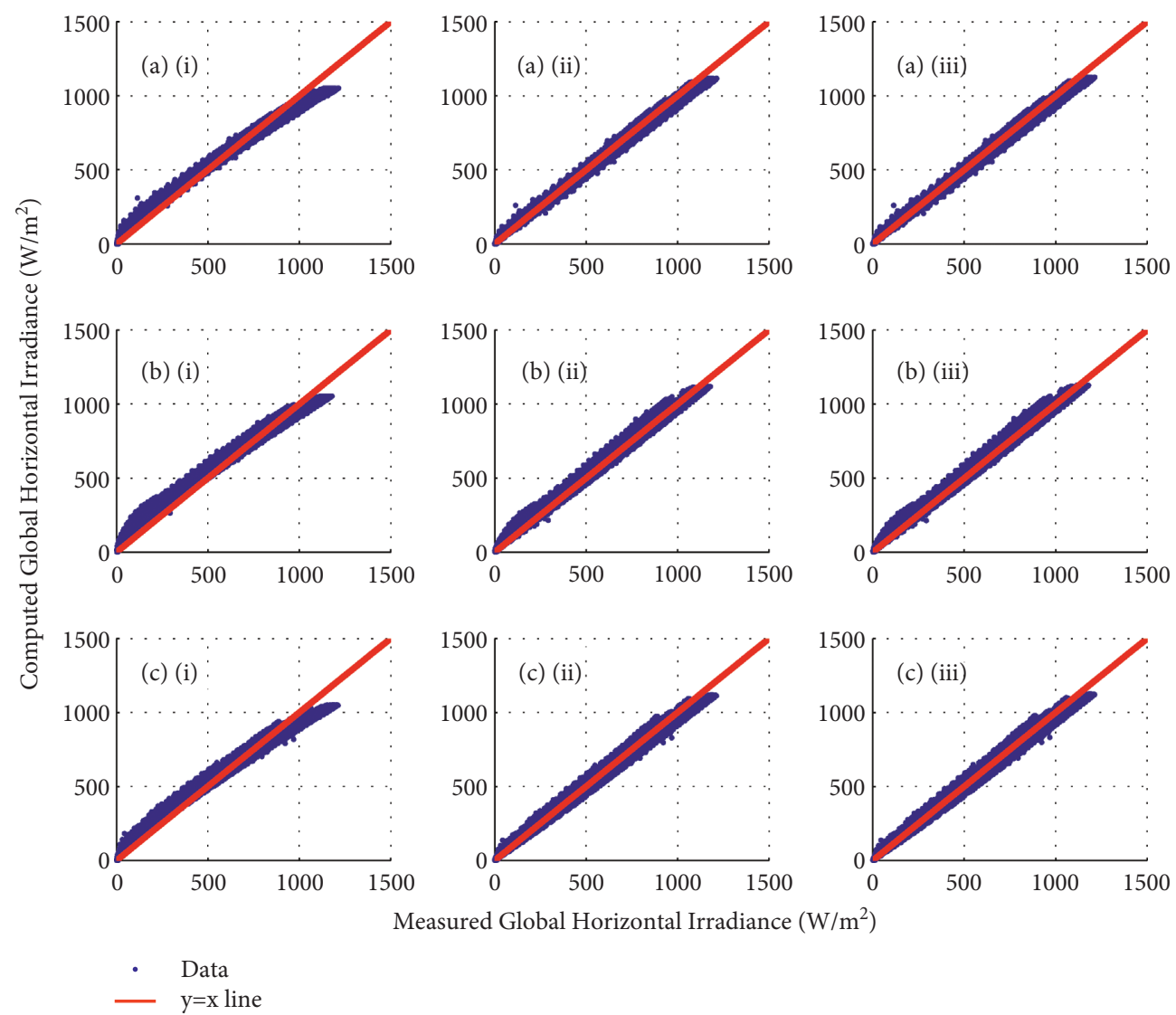

Measured Global Horizontal Irradiance $\left(\mathrm{W} / \mathrm{m}^{2}\right)$

- $\mathrm{y}=\mathrm{x}$ line

FIgure 5: Modelled vs. measured GHI at (a) Kokerboom, (b) Arandis, and (c) Auas; for (i) B-D model, (ii) R-S model, and (iii) A-B-C-G model.

4.2. Performance Evaluation of the Models. The performance of the models at the three measurement sites is presented as scatter plots in Figure 5, where good correlation between the measured and computed data is observed. The Burger- Duffie model, however, is observed to systematically overestimate the low irradiance values and underestimate the higher irradiance values. The scatter around the line $y=$ $x$ appears more symmetrical for the R-S and A-B-C-G models at Kokerboom and Auas, than at Arandis.

The systematic overestimation of low irradiance that occurs close to sunset and sunrise may be attributed to the inherent limitation of the models in accounting for atmospheric effects. Close to sun rise or sun set, there is increased absorption of the direct beam irradiance [52] and hence reduced GHI due to the longer solar path length through the atmosphere because of the low sun angle. In addition, the deviation may be attributed to the decrease in the accuracy of the measurement instruments, which normally occurs under very low global irradiance levels [47].

The monthly statistical parameters MBE, RMSE, and $R^{2}$ for the three locations are also presented in Figures 6-8 respectively. The monthly MBE presented in Figure 6 shows that, during the period from April to July, the B-D model overestimates the measured clear sky GHI, while the $\mathrm{A}-\mathrm{B}-\mathrm{C}-\mathrm{G}$ and $\mathrm{R}-\mathrm{S}$ models underestimate the clear sky $\mathrm{GHI}$ at all measurement sites. This period corresponds to wintertime during which the peak irradiance is lower because of the low sun angle compared to the summertime. This comparatively low irradiance is overestimated by the B-D model due to its poor performance compared to the other two models under low irradiance levels.

The monthly RMSE values presented in Figure 7 show that lowest RMSE values are obtained during the period from April to August. This period corresponds to winter season that is characterized by dry and very clear sky conditions. Monthly coefficient of determination, $R^{2}$, values shown in Figure 8 are generally high for all the three models, an indication of the good fit between the measured and modelled values. The $\mathrm{A}-\mathrm{B}-\mathrm{C}-\mathrm{G}$ and $\mathrm{R}-\mathrm{S}$ models, in general, show consistently higher $R^{2}$ values than obtained for the B-D model, signifying better performance of the $\mathrm{A}-\mathrm{B}-\mathrm{C}-\mathrm{G}$ and $\mathrm{R}-\mathrm{S}$ models compared to the B-D model.

The statistical error indicators for the models at the three measurement sites, over the measurement period, are shown in Table 2, where the high $R^{2}$ values observed are an indication of the model's ability to predict clear sky irradiance with great accuracy.

Based on the percentage normalized MBE (NMBE), low values (within $\pm 10 \%$ ) are obtained for both models at all measurement sites, indicating good performance. The B-D model performs better at Kokerboom and Auas, while the $\mathrm{R}-\mathrm{S}$ and the $\mathrm{A}-\mathrm{B}-\mathrm{C}-\mathrm{G}$ models perform better at Arandis. Percentage normalized RMSE (NRMSE) values show that all 

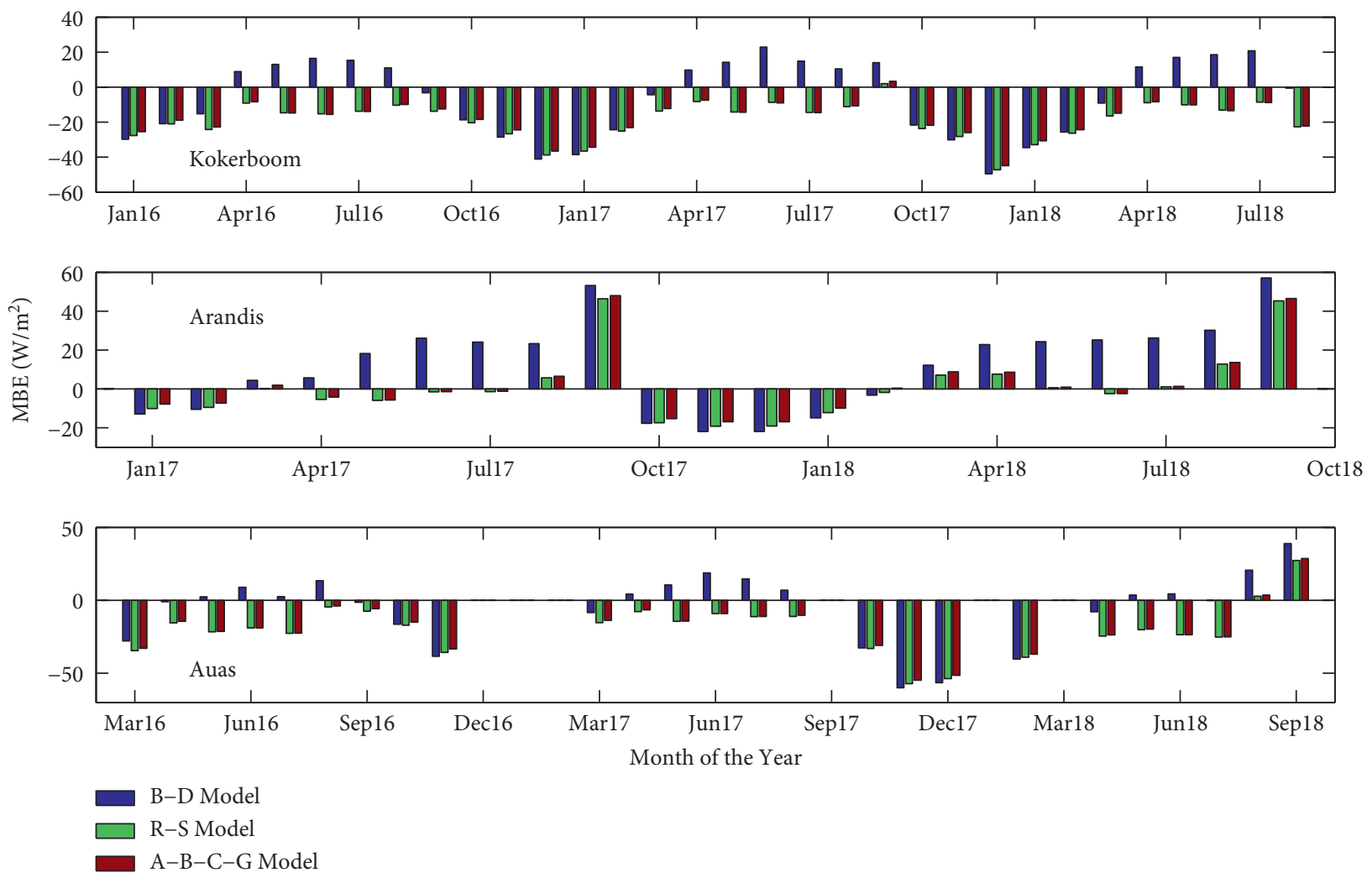

Figure 6: Monthly MBE values for Kokerboom, Arandis, and Auas.
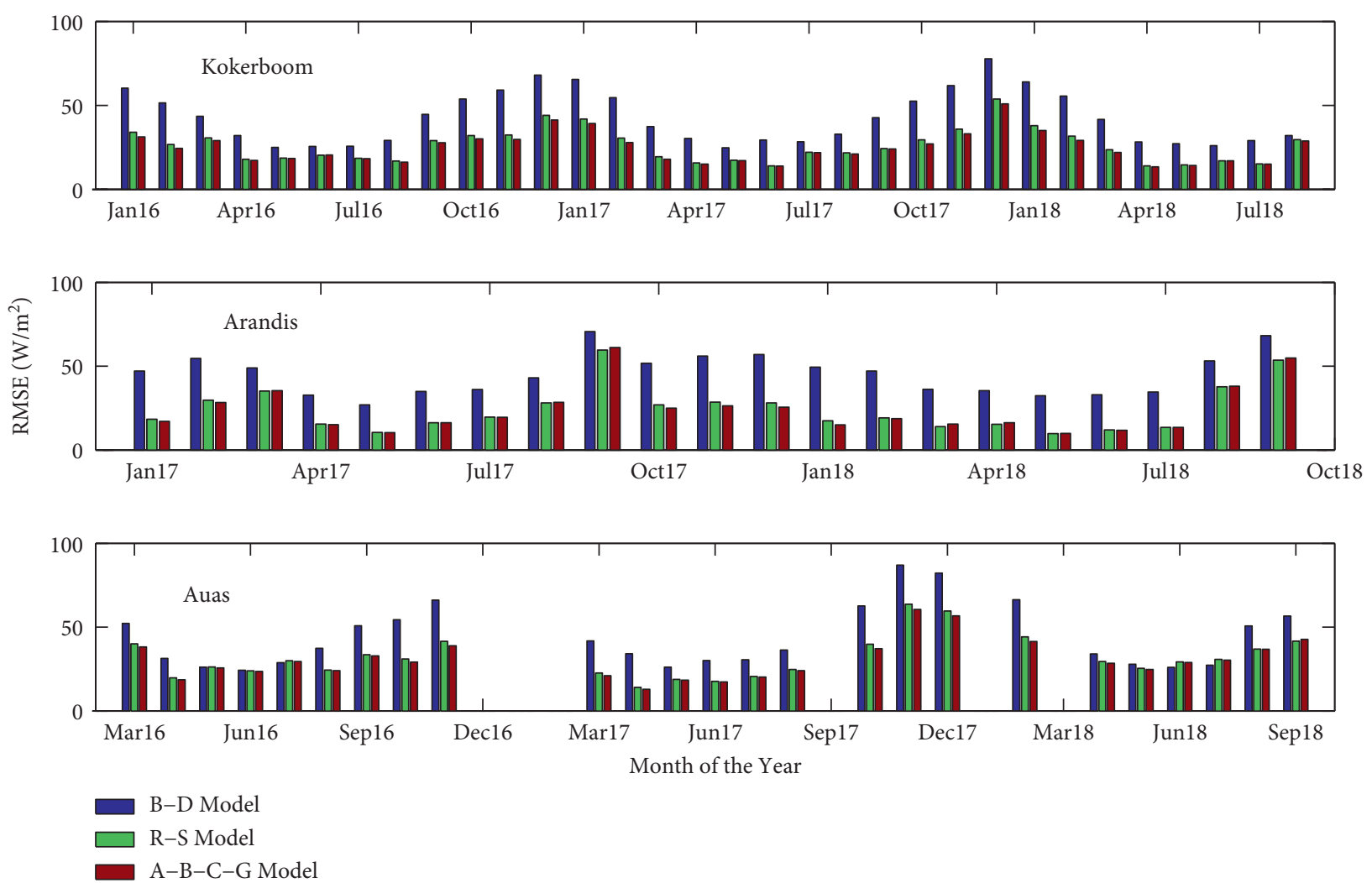

FIGURE 7: Monthly RMSE values for Kokerboom, Arandis, and Auas. 

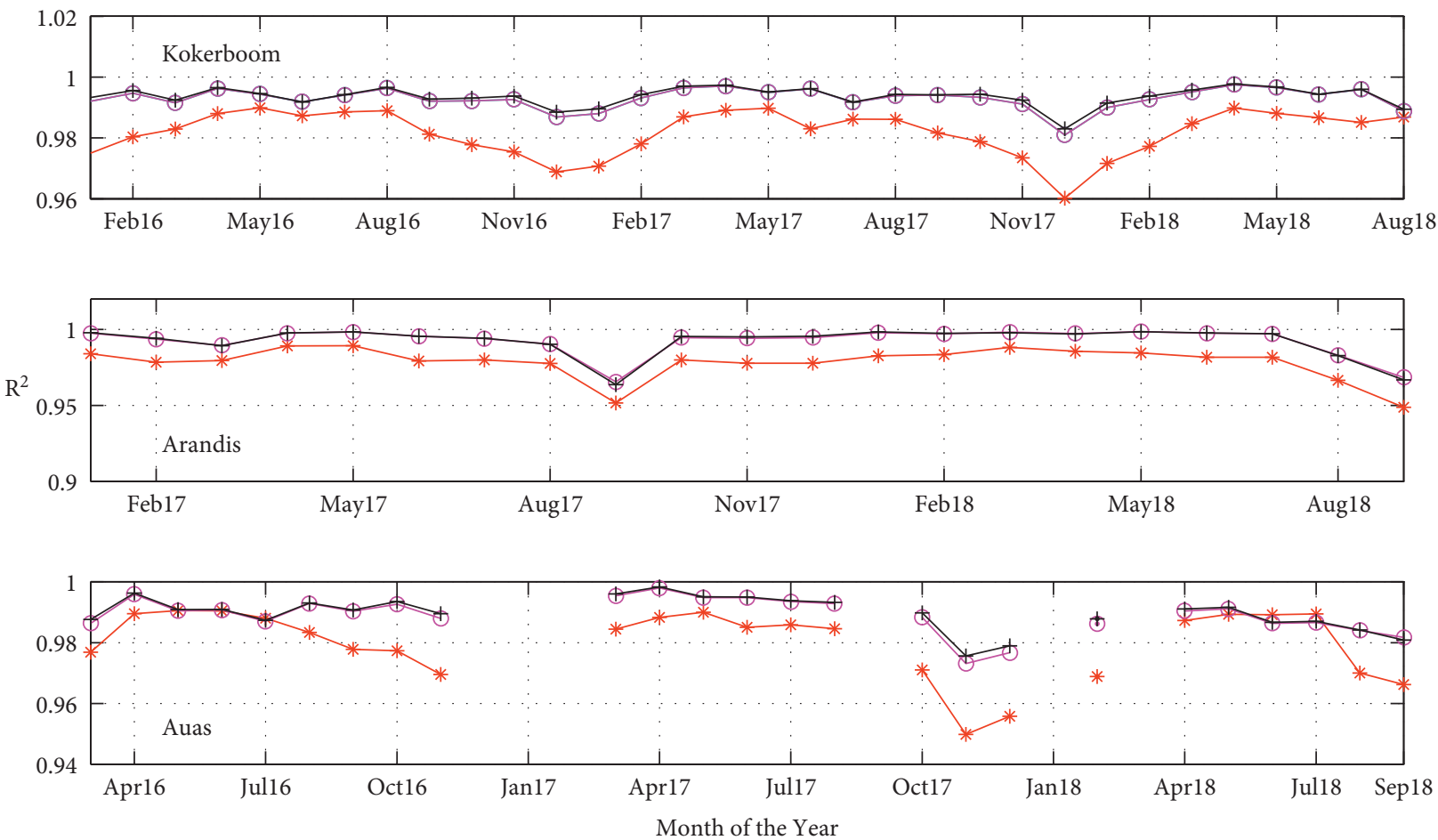

$$
\begin{array}{ll}
* & \text { B-D Model } \\
- & \text { R-S Model } \\
+ & \text { A-B-C-G Model }
\end{array}
$$

Figure 8: Monthly coefficients of determination, $R^{2}$, values for Kokerboom, Arandis, and Auas.

TABLE 2: Percentage statistical error parameters for the models at different locations.

\begin{tabular}{lccccccrrr}
\hline & \multicolumn{3}{c}{ B-D } & \multicolumn{3}{c}{ R-S } & \multicolumn{3}{c}{ A-B-C-G } \\
& NRMSE & NMBE & $R^{2}$ & NRMSE & NMBE & $R^{2}$ & NRMSE & NMBE & $R^{2}$ \\
\hline Kokerboom & 7.9 & -0.5 & 98.2 & 4.9 & -3.3 & 99.3 & 4.6 & -3.1 \\
Auas & 7.6 & 0.4 & 98.2 & 5.7 & -3.2 & 99.0 & 5.5 & -3.0 & 99.4 \\
Arandis & 8.1 & 2.6 & 98.1 & 4.5 & -0.1 & 99.4 & 4.5 & 0.1 & 99.4 \\
\hline
\end{tabular}

the three models give low NRMSE values $(<20 \%)$ and thus fit well the measured data. The A-B-C-G and R-S models consistently perform better than the B-D model, with the lowest NRMSE of $4.5 \%$ being obtained for both models at Arandis.

It seems that the B-D model, in general, gives the least accurate fit to the data and may not be appropriate for modelling the data fits, especially at radiation levels below $300 \mathrm{~W} / \mathrm{m}^{2}$. In all cases, the $\mathrm{A}-\mathrm{B}-\mathrm{C}-\mathrm{G}$ model gives the lowest NRMSE values, indicating it to be the best fit of the three models. Although evident in Table 2, the outstanding differences seen in the bar graphs of Figures 6 and 7 seem to be extreme.

The results presented in this paper refer to clear skies, including low sun conditions, and have been validated under Namibia climatic conditions. The performance of the adapted models, in general, decreases under low-sun conditions. Although the adapted models have been validated using data at three different locations in Namibia, more comprehensive investigation is required to assess their applicability at various locations across the world with similar climatic conditions.

\section{Conclusion}

To optimally design and implement solar energy projects, it is important that the solar resource for the local area be established. In areas where such irradiance measurements are not available, appropriate models, depending on the level of accuracy required and available input parameters, can be used to estimate the solar irradiance by computation of clear sky global horizontal irradiance. In this work, using three simple models adapted for the area under study, clear sky global horizontal solar irradiance (GHI) was estimated at three measurement sites in Namibia, i.e., Kokerboom, Arandis, and Auas. Clear sky days during the period under consideration were identified based on computation of clear sky index, diffuse fraction, and observation of the 
smoothness of the GHI curves. The adapted models were then calibrated and used to compute the clear sky GHI. The performance of the models in predicting clear sky GHI was evaluated by comparing the predicted/modelled irradiance with measured data at the sites and computing various statistical parameters such as MBE, RMSE, and $R^{2}$ values. Very low values of normalized MBE and RMSE and a high value for $R^{2}$ were obtained, an indication of good fitting between modelled results and measured data. The A-B-C-G and $\mathrm{R}-\mathrm{S}$ models were observed to perform better compared to the B-D model and therefore could be used in computing/ estimating clear sky GHI irradiance in Namibia and other regions with similar climatic conditions, especially in areas where no such measurements are available but are needed for the design and implementation of solar energy power projects.

\section{Nomenclature}

\begin{tabular}{|c|c|}
\hline A-B-C-G: & Adnot-Bourges-Campana-Gicquel model \\
\hline ANN: & Artificial neural network \\
\hline a.s.l: & Above sea level \\
\hline $\mathrm{B}-\mathrm{D}:$ & Berger-Duffie model \\
\hline DNI: & Direct normal irradiance $\left(\mathrm{W} / \mathrm{m}^{2}\right)$ \\
\hline$E_{0}:$ & Eccentricity correction \\
\hline GHI: & Global horizontal irradiance $\left(\mathrm{W} / \mathrm{m}^{2}\right)$ \\
\hline $\mathrm{GHI}_{i, c}$ : & $\begin{array}{l}i^{\text {th }} \text { computed global horizontal irradiance } \\
\left(\mathrm{W} / \mathrm{m}^{2}\right)\end{array}$ \\
\hline $\mathrm{GHI}_{i, m}:$ & $\begin{array}{l}i^{\text {th }} \text { measured global horizontal irradiance } \\
\left(\mathrm{W} / \mathrm{m}^{2}\right)\end{array}$ \\
\hline$H_{0}:$ & Extraterrestrial solar irradiance $\left(\mathrm{W} / \mathrm{m}^{2}\right)$ \\
\hline$H:$ & Global solar irradiance $\left(\mathrm{W} / \mathrm{m}^{2}\right)$ \\
\hline$H_{0 d}:$ & $\begin{array}{l}\text { Daily extraterrestrial solar radiation } \\
\text { (Wh/m } / \mathrm{m}^{2} \text { per day) }\end{array}$ \\
\hline$I_{s c}:$ & Solar constant $\left(\mathrm{W} / \mathrm{m}^{2}\right)$ \\
\hline$K:$ & Diffuse fraction \\
\hline$K_{t}:$ & Clearness index \\
\hline MBE: & Mean bias error \\
\hline$n:$ & Day of year \\
\hline NEI: & Namibia Energy Institute \\
\hline NMBE: & Normalized mean bias error $(\%)$ \\
\hline NRMSE: & Normalized root mean square error (\%) \\
\hline PV: & Photovoltaic \\
\hline$R^{2}:$ & Coefficient of determination \\
\hline RMSE: & Root mean square error \\
\hline R-S: & Robledo-Soler model \\
\hline$\omega:$ & Hour angle $\left(^{\circ}\right)$ \\
\hline$\omega_{s}:$ & Sunrise hour angle $\left({ }^{\circ}\right)$ \\
\hline$\varphi:$ & Latitude $\left({ }^{\circ}\right)$ \\
\hline$\delta:$ & Declination angle $\left(^{\circ}\right)$ \\
\hline$z:$ & Zenith angle $\left({ }^{\circ}\right)$. \\
\hline
\end{tabular}

\section{Data Availability}

The data that support the findings of this study are available from NEI. Restrictions apply to the availability of these data, which were used under license for this study. Data are available from the authors upon reasonable request and with the permission of NEI.

\section{Conflicts of Interest}

The authors declare that there are no conflicts of interest.

\section{Acknowledgments}

The authors wish to thank the Namibia Energy Institute (NEI) for providing access to the irradiance data measured at Kokerboom, Arandis, and Auas.

\section{References}

[1] C. A. Gueymard, "Clear-sky irradiance predictions for solar resource mapping and large-scale applications: improved validation methodology and detailed performance analysis of 18 broadband radiative models," Solar Energy, vol. 86, no. 8, pp. 2145-2169, 2012.

[2] A. Pérez-Burgos, M. Díez-Mediavilla, C. Alonso-Tristán, and M. C. Rodríguez-Amigo, "Analysis of solar direct irradiance models under clear-skies: evaluation of the improvements for locally adapted models," Journal of Renewable and Sustainable Energy, vol. 9, no. 2, Article ID 023703, 2017.

[3] P. Ineichen, "Validation of models that estimate the clear sky global and beam solar irradiance," Solar Energy, vol. 132, pp. 332-344, 2016.

[4] L. A. Hunt, L. Kuchar, and C. J. Swanton, "Estimation of solar radiation for use in crop modelling," Agricultural and Forest Meteorology, vol. 91, no. 3-4, pp. 293-300, 1998.

[5] V. Badescu, C. A. Gueymard, S. Cheval et al., "Computing global and diffuse solar hourly irradiation on clear sky. Review and testing of 54 models," Renewable and Sustainable Energy Reviews, vol. 16, no. 3, pp. 1636-1656, 2012.

[6] O. E. Alani, H. Ghennioui, A. Ghennioui, and D. Fatimaezzahra, "Detection of clear sky instants from high frequencies pyranometric measurements of global horizontal irradiance," E3S Web of Conferences, vol. 229, 2021.

[7] S. Pattarapanitchai and S. Janjai, "A semi-empirical model for estimating diffuse solar irradiance under a clear sky condition for a tropical environment," Procedia Engineering, vol. 32, pp. 421-426, 2012.

[8] R. E. Bird and R. L. Hulstrom, A Simplified Clear Sky Model for Direct and Diffuse Insolation on Horizontal Surfaces, Solar Energy Institute, Golden, CO, USA, 1981.

[9] A. Ianetz and A. Kudish, "A method for determining the solar global and defining the diffuse and beam irradiation on a clear day," in Modeling Solar Radiation at the Earth's SurfaceSpringer, Berlin, Germany, 2008.

[10] C. A. Gueymard, "REST2: high-performance solar radiation model for cloudless-sky irradiance, illuminance, and photosynthetically active radiation - validation with a benchmark dataset," Solar Energy, vol. 82, no. 3, pp. 272-285, 2008.

[11] J. E. Hay, "Satellite based estimates of solar irradiance at the earth's surface-I. Modelling approaches," Renewable Energy, vol. 3, no. 4-5, pp. 381-393, 1993.

[12] S. C. Nwokolo and J. C. Ogbulezie, "A qualitative review of empirical models for estimating diffuse solar radiation from experimental data in Africa," Renewable and Sustainable Energy Reviews, vol. 92, pp. 353-393, 2018.

[13] H. C. Bayrakçı, C. Demircan, and A. Keçebaş, "The development of empirical models for estimating global solar radiation on horizontal surface: a case study," Renewable and Sustainable Energy Reviews, vol. 81, pp. 2771-2782, 2018. 
[14] S. Benkaciali, M. Haddadi, and A. Khellaf, "Evaluation of direct solar irradiance from 18 broadband parametric models: case of algeria," Renewable Energy, vol. 125, pp. 694-711, 2018.

[15] M. Lefèvre, A. Oumbe, P. Blanc et al., "McClear: a new model estimating downwelling solar radiation at ground level in clear-sky conditions," Atmospheric Measurement Techniques, vol. 6 , no. 9, pp. 2403-2418, 2013.

[16] J. Antonanzas, R. Urraca, F. J. Martinez-de-Pison, and F. Antonanzas-Torres, "Solar irradiation mapping with exogenous data from support vector regression machines estimations," Energy Conversion and Management, vol. 100, pp. 380-390, 2015.

[17] J. A. Ruiz-Arias and C. A. Gueymard, "Worldwide intercomparison of clear-sky solar radiation models: consensusbased review of direct and global irradiance components simulated at the earth surface," Solar Energy, vol. 168, pp. 10-29, 2018.

[18] M. Noia, C. F. Ratto, and R. Festa, "Solar irradiance estimation from geostationary satellite data: I. Statistical models," Solar Energy, vol. 51, no. 6, pp. 449-456, 1993.

[19] H. G. Beyer, C. Costanzo, and D. Heinemann, "Modifications of the heliosat procedure for irradiance estimates from satellite images," Solar Energy, vol. 56, no. 3, pp. 207-212, 1996.

[20] L. F. Zarzalejo, J. Polo, L. Martín, L. Ramírez, and B. Espinar, "A new statistical approach for deriving global solar radiation from satellite images," Solar Energy, vol. 83, no. 4, pp. 480-484, 2009.

[21] D. Cano, J. M. Monget, M. Albuisson, H. Guillard, N. Regas, and L. Wald, "A method for the determination of the global solar radiation from meteorological satellite data," Solar Energy, vol. 37, no. 1, pp. 31-39, 1986.

[22] J. Polo, F. Antonanzas-Torres, J. M. Vindel, and L. Ramirez, "Sensitivity of satellite-based methods for deriving solar radiation to different choice of aerosol input and models," Renewable Energy, vol. 68, pp. 785-792, 2014.

[23] G. Huang, Z. Li, X. Li et al., "Estimating surface solar irradiance from satellites: past, present, and future perspectives," Remote Sensing of Environment, vol. 233, Article ID 111371, 2019.

[24] M. Sahan and E. Yakut, "Estimation of monthly global solar radiation in the eastern Mediterranean region in Turkey by using artificial neural networks," EPJ Web of Conferences, vol. 128, Article ID 06001, 2016.

[25] M. Ozgoren, M. Bilgili, and B. Sahin, "Estimation of global solar radiation using ANN over Turkey," Expert Systems with Applications, vol. 39, no. 5, pp. 5043-5051, 2012.

[26] S. Kumar and T. Kaur, "Efficient solar radiation estimation using cohesive artificial neural network technique with optimal synaptic weights," Proceedings of the Institution of Mechanical Engineers-Part A: Journal of Power and Energy, vol. 234, no. 6, pp. 862-873, 2019.

[27] A. Hasni, A. Sehli, B. Draoui, A. Bassou, and B. Amieur, "Estimating global solar radiation using artificial neural network and climate data in the south-western region of Algeria," Energy Procedia, vol. 18, pp. 531-537, 2012.

[28] F. Besharat, A. A. Dehghan, and A. R. Faghih, "Empirical models for estimating global solar radiation: a review and case study," Renewable and Sustainable Energy Reviews, vol. 21, pp. 798-821, 2013.

[29] J. Basharat and A. Naiem, "Comparative analysis of diffuse solar radiation models based on sky-clearness index and sunshine period for humid-subtropical climatic region of India: a case study," Renewable and Sustainable Energy Reviews, vol. 78, pp. 329-355, 2017.
[30] C. N. Long and T. P. Ackerman, "Identification of clear skies from broadband pyranometer measurements and calculation of downwelling shortwave cloud effects," Journal of Geophysical Research: Atmospheres, vol. 105, no. D12, pp. 15609-15626, 2000.

[31] R. Chauvin, J. Nou, S. Thil, and S. Grieu, "A new approach for assessing the clear-sky direct normal irradiance in real time," vol. 40, no. 15-16, pp. 7245-7264, 2016.

[32] I. Vamvakas, V. Salamalikis, and A. Kazantzidis, "Evaluation of enhancement events of global horizontal irradiance due to clouds at Patras, South-West Greece," Renewable Energy, vol. 151, pp. 764-771, 2020.

[33] P. Tzoumanikas, E. Nikitidou, A. F. Bais, and A. Kazantzidis, "The effect of clouds on surface solar irradiance, based on data from an all-sky imaging system," Renewable Energy, vol. 95, pp. 314-322, 2016.

[34] P. A. Abhnil, T. A. Robert, and K. Merlinde, "Assessment of direct normal irradiance and cloud connections using satellite data over Australia," Applied Energy, vol. 143, pp. 301-311, 2015.

[35] R. . D. Tapakis and A. G. Charalambides, "Monitoring cloud motion in Cyprus for solar irradiance prediction," Conference Papers in Science, vol. 2013, pp. 1-6, 2013.

[36] C. A. Gueymard, J. M. Bright, D. Lingfors, A. Habte, and M. Sengupta, "A posteriori clear-sky identification methods in solar irradiance time series: review and preliminary validation using sky imagers," Renewable and Sustainable Energy Reviews, vol. 109, pp. 412-427, 2019.

[37] A. Cazorla, C. Husillos, M. Antón, and L. Alados-Arboledas, "Multi-exposure adaptive threshold technique for cloud detection with sky imagers," Solar Energy, vol. 114, pp. 268-277, 2015.

[38] M. J. Reno and C. W. Hansen, "Identification of periods of clear sky irradiance in time series of GHI measurements," Renewable Energy, vol. 90, pp. 520-531, 2016.

[39] M. Iqbal, An Introduction to Solar Radiation, Academic Press, London, UK, 1983.

[40] J. A. Duffie and W. A. Beckman, Solar Engineering of Thermal Processes, John Wiley \& Sons, Hoboken, NJ, USA, 2013.

[41] S. A. Kalogirou, "Environmental characteristics," in Solar Energy Engineering, pp. 49-762, Academic Press, Cambridge, MA, USA, 2009.

[42] M. Alves, L. Sanches, J. Nogueira, and V. Silva, "Effects of sky conditions measured by the clearness index on the estimation of solar radiation using a digital elevation model," Atmospheric and Climate Sciences, vol. 3, no. 4, pp. 618-626, 2013.

[43] D. H. W. Li and J. C. Lam, "An analysis of climatic parameters and sky condition classification," Building and Environment, vol. 36, no. 4, pp. 435-445, 2001.

[44] Y. Jung, H. Lee, J. Kim, Y. Cho, J. Kim, and Y. Lee, "Spatiotemporal characteristics in the clearness index derived from global solar radiation observations in korea," Atmosphere, vol. 7 , no. 4, p. 55, 2016.

[45] D. Djafer, A. Irbah, and M. Zaiani, "Identification of clear days from solar irradiance observations using a new method based on the wavelet transform," Renewable Energy, vol. 101, pp. 347-355, 2017.

[46] M. Alia-Martinez, J. Antonanzas, R. Urraca, F. J. Martinez-dePison, and F. Antonanzas-Torres, "Benchmark of algorithms for solar clear-sky detection," Journal of Renewable and Sustainable Energy, vol. 8, no. 3, Article ID 033703, 2016.

[47] V. Badescu, "Verification of some very simple clear and cloudy sky models to evaluate global solar irradiance," Solar Energy, vol. 61, no. 4, pp. 251-264, 1997. 
[48] L. Robledo and A. Soler, "Luminous efficacy of global solar radiation for clear skies," Energy Conversion and Management, vol. 41, no. 16, pp. 1769-1779, 2000.

[49] J. Stein, C. Hansen, and M. Reno, "Global horizontal irradiance clear sky models: implementation and analysis," 2012.

[50] Kipp and B. V. Zenon, "CMP10 pyranometer," 2019, https:// www.kippzonen.com/Product/276/CMP10-Pyranometer\#. YCZhOnlRWUk.

[51] H. Suehrcke and P. G. McCormick, "The diffuse fraction of instantaneous solar radiation," Solar Energy, vol. 40, no. 5, pp. 423-430, 1988.

[52] J. Landsberg and P. Sands, "Weather and energy balance," in Physiological Ecology of Forest Production: Principles, Processes and Models, Terrestrial Ecology, pp. 13-48, Elsevier Science, Amsterdam, Netherlands, 2011. 